8 - ORIGINAL ARTICLE

CLINICAL INVESTIGATION

\title{
Comparing the pain of propofol via different combinations of fentanyl, sufentanil or remifentanil in gastrointestinal endoscopy ${ }^{1}$
}

\author{
Lifeng Zhang', Yang Bao ${ }^{I}$, Dongping Shi ${ }^{I}$ \\ DOI: http://dx.doi.org/10.1590/S0102-8650201400160008
}

IPhD, Department of Anesthesiology, Shanghai Jiading Central Hospital, Shanghai, China. Design of the study, acquisition of data, carrying out the study. IIMaster, Department of Anesthesiology, Shanghai Jiading Central Hospital, Shanghai, China. Carrying out the study, manuscript writing.

\begin{abstract}
PURPOSE: To evaluate the pain on injection of propofol via different combinations of fentanyl, sufentanil or remifentanil in gastrointestinal endoscopy.

METHODS: Total 439 patients were randomly allocated into 6 groups. Propofol \& fentanil (PF) group received $1 \mu \mathrm{g} / \mathrm{kg}$ fentanyl, propofol \& sufentanil (PS) group received $0.1 \mu \mathrm{g} / \mathrm{kg}$ sufentanil and propofol \& remifentanyl (PR) group received $1 \mu \mathrm{g} / \mathrm{kg}$ remifentanyl prior to administration of $1-2 \mathrm{mg} / \mathrm{kg}$ of propofol. The propofol \& half-fentanil (Pf) group, propofol \& half-sufentanil (Ps) group and propofol \& half-remifentanyl (Pr) group were given $0.5 \mu \mathrm{g} / \mathrm{kg}$ fentanyl, $0.05 \mu \mathrm{g} / \mathrm{kg}$ sufentanil and $0.5 \mu \mathrm{g} / \mathrm{kg}$ remifentanyl, respectively and later administrated 1-2 mg/kg propofol. All patients were monitored for the blood pressure (MAP), heart rate (HR), and oxygen saturation $\left(\mathrm{SpO}_{2}\right)$. Additionally, the pain intensity was assessed using a 4-point verbal rating scale (VRS) by professional doctors.
\end{abstract}

RESULTS: The incidence of pain due to propofol injection in Ps group (33.8\%) was significantly lower than other 5 groups. The heart rate (HR) and mean arterial pressure (MAP) were maintained within the normal limits in all six groups and there was no hypotension or bradycardia encountered during the study period.

CONCLUSION: Propofol and sufentanil group was the most suitable program for painless gastroscopy.

Key words: Gastrointestinal Endoscopy. Propofol. Fentanyl. Sufentanil. Remifentanil. 


\section{Introduction}

Gastrointestinal endoscopy, an invasive examination method, is one of the most common interventional medical procedures carried out worldwide. And usually, sedation is administrated to the patients scheduling to undergo gastrointestinal endoscopy for the purpose of analgesia, amnesia, controlling the behavior of patient during the procedure, well completing the endoscopy and prompt patient recovery to the pretreatment level of consciousness ${ }^{1}$.

Propofol is a short-acting, intravenously administered hypnotic agent, which slows the channel-closing time and also acts as a sodium channel blocker ${ }^{2}$ through activating GABA receptor ${ }^{3}$. Due to the high lipid solubility and short half-life, the onset of action of propofol is almost instantaneous and the recovery is rapid that make it into a desired sedative agent for short duration procedures such as gastrointestinal endoscopy ${ }^{4}$. Propofol appears to be an attractive endoscopic sedation among gastroenterologists and mow has been used extensively for gastrointestinal endoscopy ${ }^{5}$. It often has been administrated as a single agent. However, propofol injection frequently causes local pain or discomfort that sometimes induces distress to patients ${ }^{6,7}$. Novel approach to propofol administration in combination with opioids has been proposed to improve sedation and analgesia ${ }^{8-11}$. Fentanyl is a potent, synthetic opioid analgesic with a rapid onset and short duration of action, and is commonly used in preprocedures as a pain reliever as well as an anesthetic in combination with a benzodiazepine ${ }^{12}$. Sufentanil is a powerful synthetic opioid drug, approximately 5 to 10 times more potent than fentanyl ${ }^{13}$ Remifentanil, another opioid medicine, is used for sedation as well as combined with other medications for use in general anesthesia ${ }^{14}$ 15. Besides, when used alone, relatively large doses of propofol may be required to achieve adequate comfort which may result in doserelated side effects, such as hypotension or respiratory depression ${ }^{16}$,

${ }^{17}$. Drug combinations can decrease the adverse reactions by reducing the dosage of drugs ${ }^{18}$.

Studies on side effects of drug combination of propofol were not enough, and the anesthesia mechanism was not very clear. So we conducted a double blinded and random control study to compare the clinical efficacy and safety of anesthesia for gastrointestinal endoscopy using propofol via different combinations of fentanyl, sufentanil or remifentanil and to choose a more suitable sedation approach for gastrointestinal endoscopy.

\section{Methods}

The study was approved by the institutional review board. From March, 2011 to April, 2013, 439 American Society of Anesthesiologists physical status I or II patients, aged 20-65 years, who scheduled to receive a gastrointestinal endoscopy examination were included (Table 1).

TABLE 1 - Demographic data.

\begin{tabular}{lcccccc}
\hline & $\begin{array}{c}\text { PF } \\
(\mathrm{n}=100)\end{array}$ & $\begin{array}{c}\text { PS } \\
(\mathrm{n}=89)\end{array}$ & $\begin{array}{c}\text { PR } \\
(\mathrm{n}=16)\end{array}$ & $\begin{array}{c}\text { Pf } \\
(\mathrm{n}=90)\end{array}$ & $\begin{array}{c}\text { Ps } \\
(\mathrm{n}=80)\end{array}$ & $\begin{array}{c}\text { Pr } \\
(\mathrm{n}=64)\end{array}$ \\
\hline Sex(M/F) & $45 / 55$ & $48 / 41$ & $7 / 9$ & $46 / 44$ & $44 / 36$ & $37 / 27$ \\
Age(yr $)$ & 44.8 & 45.6 & 45.9 & 45.9 & 46.9 & 47.5 \\
& $(13.7)$ & $(14.4)$ & $(12.7)$ & $(13.4)$ & $(14.2)$ & $(14.3)$ \\
Weight & 62.4 & 62.4 & 59.7 & 61.1 & 62.4 & 63.2 \\
& $(9.1)$ & $(8.7)$ & $(9.4)$ & $(10.4)$ & $(7.5)$ & $(6.4)$ \\
Height & 157.8 & 165.3 & 163.1 & 164.6 & 165.3 & 164.9 \\
& $(8.2)$ & $(8.8)$ & $(7.6)$ & $(6.8)$ & $(5.8)$ & $(7.0)$ \\
\hline
\end{tabular}

PF: Propofol \& sufentanil, PS: propofol \& sufentanil, PR: propofol \& remifentanyl, Pf:propofol \& half-sufentanil, Ps: propofol \& half-sufentanil, Pr: propofol \& halfremifentanyl.

Values are shown as mean (SD) or number of patients. There were no significant differences between groups.

\section{Gastrointestinal endoscopy and drug administration}

All patients were allocated randomly into 6 groups using a computer generated randomization list manipulated by a statistician. Before examination no patient received diet and preanesthetic medications. On arriving at the operating room, the patients were monitored for the blood pressure (MAP), heart rate (HR) and oxygen saturation $\left(\mathrm{SpO}_{2}\right)$ using a monitoring device (Dash 3000). The patients maintained left-lateral lie and received oxygen insufflations at a rate of $2 \mathrm{~L} / \mathrm{min}$. The patients in $\mathrm{PF}$ group (propofol \& fentanyl), PS group (propofol \& sufentanil) or PR group (propofol \& remifentanyl) respectively received the fentanyl of $1 \mu \mathrm{g} / \mathrm{kg}$, sufentanil of $0.1 \mu \mathrm{g} / \mathrm{kg}$ or remifentanyl of 1 $\mu \mathrm{g} / \mathrm{kg}$ intravenously (diluted with normal saline) for $30 \mathrm{~s}$ and 60 $\mathrm{s}$ and later were given the propofol of $1-2 \mathrm{mg} / \mathrm{kg}$ for $60 \mathrm{~s}$. The patients in Pf group (propofol \& half-fentanil), Ps group (propofol $\&$ half-sufentanil) or Pr group (propofol \& half-remifentanyl) were given the fentanyl of $0.5 \mu \mathrm{g} / \mathrm{kg}$, sufentanil of $0.05 \mu \mathrm{g} / \mathrm{kg}$ and remifentanyl of $0.5 \mu \mathrm{g} / \mathrm{kg}$, respectively over a $30 \mathrm{~s}$ period and later were given the propofol of $1-2 \mathrm{mg} / \mathrm{kg}$ intravenously over a $60 \mathrm{~s}$ period. There was a $15-30 \mathrm{~s}$ period between the administration of opioid and propofol. The patients received the gastroscopy after the eyelash reflex vanished. The patients with cough or body movement were given additional propofol of $0.5-1 \mathrm{mg} / \mathrm{kg}$.

\section{Assessment of pain intensity using 4-point verbal rating scale}

Immediately after injected with the propofol, the patients were asked about pain at the injection site and the 
pain intensity was assessed using a 4-point verbal rating scale (VRS) by an anesthetist blinded to the drug administration. This VRS assessment was developed by McCrirrick and Hunter10 and has been previously applied (by the present investigators) to evaluate the pain intensity on injection of propofol. The 0 represents no pain (no reaction to the injection); The 1 represents mild pain (a minor verbal/facial response or motor reaction to the injection); The 2 represents moderate pain (a clear verbal/facial response or motor reaction to the injection); and The 3 represents severe pain (the patient both complained of pain and withdrew their arm) ${ }^{19}$.

\section{Statistical analysis}

Data were presented by mean \pm standard deviations and statistical software SPSS18.0 ${ }^{20}$ was applied. A Fisher's exact test ${ }^{21}$ was used to calculate the between-group differences in the incidence of microemulsion-induced pain, and a Kruskal-Wallis test ${ }^{22}$ was used to assess the differences in the mean pain-intensity scores. $P<0.05$ was considered statistically significant.

\section{Results}

Changes of MAP, HR, and $\mathrm{SpO}$

The heart rate (HR), mean arterial pressure (MAP) and $\mathrm{SpO}_{2}$ were maintained within the normal limits in six groups. There was no hypotension or bradycardia encountered during the study (Table 2).

\section{The parameters comparison of painless gastroscopy of propofol}

In Table 3, the doses of propofol in another five groups were similar except PR group (Table 3). The patients in the PR

TABLE 2 - Changes of MAP, HR, and $\mathrm{SpO}_{2}$ at different time point.

\begin{tabular}{lccccc}
\hline & Group & Before gastroscope & Gastroscope over a throat & Gastroscope & After gastroscope \\
\hline MAP $(\mathrm{mmHg})$ & PF & $87.52 \pm 10.31$ & $79.15 \pm 10.15$ & $78.64 \pm 8.52$ & $89.51 \pm 11.63$ \\
& PS & $88.34 \pm 9.83$ & $77.03 \pm 8.39$ & $78.64 \pm 8.85$ & $88.74 \pm 8.73$ \\
& PR & $89.28 \pm 10.02$ & $76.19 \pm 7.89$ & $77.53 \pm 7.84$ & $87.16 \pm 9.62$ \\
& Pf & $87.28 \pm 9.37$ & $78.43 \pm 9.52$ & $79.56 \pm 10.64$ & $86.74 \pm 8.84$ \\
& Ps & $88.83 \pm 8.25$ & $78.06 \pm 11.13$ & $77.36 \pm 8.84$ & $89.28 \pm 8.48$ \\
& Pr & $87.56 \pm 9.69$ & $76.95 \pm 8.52$ & $75.26 \pm 8.36$ & $78.73 \pm 7.83$ \\
$\mathrm{HR}\left(\mathrm{min}^{-1}\right)$ & PF & $79.52 \pm 9.65$ & $76.76 \pm 7.42$ & $77.63 \pm 9.26$ & $79.62 \pm 9.73$ \\
& PS & $80.45 \pm 10.53$ & $78.63 \pm 8.83$ & $75.26 \pm 7.36$ & $76.84 \pm 7.26$ \\
& PR & $78.62 \pm 6.26$ & $75.63 \pm 7.74$ & $78.73 \pm 7.47$ & $80.67 \pm 8.95$ \\
$\mathrm{SpO}_{2}(100 \%)$ & Pf & $81.62 \pm 9.57$ & $79.33 \pm 8.46$ & $75.73 \pm 7.84$ & $78.94 \pm 7.95$ \\
& Ps & $79.63 \pm 9.63$ & $76.63 \pm 7.26$ & $99.10 \pm 1.18$ & $79.26 \pm 7.37$ \\
& Pr & $79.73 \pm 8.63$ & $77.62 \pm 6.87$ & $98.90 \pm 1.21$ & $99.12 \pm 1.20$ \\
& PF & $99.50 \pm 0.63$ & $99.00 \pm 1.15$ & $98.12 \pm 1.28$ & $98.92 \pm 1.22$ \\
& PS & $99.30 \pm 0.52$ & $98.80 \pm 1.19$ & $99.12 \pm 1.10$ & $99.02 \pm 1.03$ \\
& PR & $99.46 \pm 0.45$ & $98.76 \pm 1.30$ & $98.88 \pm 1.06$ & $99.04 \pm 1.20$ \\
& Pf & $99.34 \pm 0.46$ & $98.78 \pm 1.24$ & $98.90 \pm 1.02$ & $98.78 \pm 1.08$ \\
\hline
\end{tabular}

PF: Propofol \& sufentanil, PS: propofol \& sufentanil, PR: propofol \& remifentanyl, Pf: propofol \& half-sufentanil, Ps: propofol \& half-sufentanil, Pr: propofol \& halfremifentanyl. MAP: the blood pressure, HR: heart rate, SpO2: oxygen saturation.

The differences between two groups aren't significant enough ( $\mathrm{p}>0.05)$ indicates no significant differences).

TABLE 3 - The parameters of six groups during the anesthesia in gastrointestinal endoscopy.

\begin{tabular}{lccccc}
\hline & Dose of propofol & Times of body movement (ave) & Eyelashreflex (times) & Manipulate time (min) & Revival time (min) \\
\hline PF & $96.3 \pm 5.5$ & $0.030 \pm 0.003$ & $64.9 \pm 4.5$ & $122.4 \pm 8.6$ \\
PS & $92.3 \pm 4.1$ & $0.068 \pm 0.004$ & $67.7 \pm 4.3$ & $137.2 \pm 7.3$ & $94.6 \pm 9.4$ \\
PR & $110.7 \pm 4.3^{*}$ & $0.867 \pm 0.006^{*}$ & $80.2 \pm 3.2^{*}$ & $169.0 \pm 11.3^{*}$ & $91.8 \pm 7.4$ \\
Pf & $91.6 \pm 5.3$ & $0.057 \pm 0.014$ & $64.8 \pm 3.5$ & $132.1 \pm 10.5$ & $96.4 \pm 4.3$ \\
Ps & $95.8 \pm 5.4$ & $0^{*}$ & $58.6 \pm 3.3$ & $137.8 \pm 9.5$ & $93.2 \pm 6.5$ \\
Pr & $89.9 \pm 4.7$ & $0.079 \pm 0.003$ & $63.8 \pm 4.1$ & $178.2 \pm 11.8$ \\
\hline
\end{tabular}

PF: Propofol \& sufentanil, PS: propofol \& sufentanil, PR: propofol \& remifentanyl,

Pf: propofol \& half-sufentanil, Ps: propofol \& half-sufentanil, Pr: propofol \& half-remifentanyl.

${ }^{*}, \mathrm{p}<0.05$ indicates significant differences. 
group appeared respiratory and HR depression, and needed the respiratory support and assistance of atropine, which significantly affect the safety of outpatient, so this program was not suitable for clinical gastrointestinal endoscopy. Differences were observed in times of eyelashreflex, manipulate time and recovery time, but not significant. It was important to point out that there was no body movement in Ps group, which indicated the better anesthesia effect of Ps group than other groups.

\section{Incidence and severity of pain on a propofol injection}

The incidence of pain from Ps group (33.8\%) was significantly lower than other five groups $(47.0 \%, 41.6 \%, 43.8 \%$, $42.2 \%$, and $43.8 \%$ ). The incidence of moderate pain was only $2.5 \%$, and no case of severe pain was observed in all six groups (Table 4).

\section{Discussion}

Action mechanism and significance of combination of propofol and opioids

Propofol-induced pain has been ranked by American anesthesiologists as the seventh most important problem of current clinical anesthesiology ${ }^{23}$. The mechanism by which propofol causes pain on injection is not fully understood. Site of injection, injection speed and carrier fluids ${ }^{24}$, dilutions ${ }^{25}$, temperatures ${ }^{19}$, and concomitant therapies have been investigated, according to which clinical strategies for the prevention of propofol injection pain have been suggested with varying degrees of success ${ }^{26}$. Intravenous administration of local analgesic is a common pretreatment for reducing such pain. Opioids, psychoactive chemicals, are

TABLE 4 - Incidence and severity of pain in six groups.

\begin{tabular}{lcccccc}
\hline Severity of pain & PF (100) & PS (89) & PR (16) & Pf (90) & Ps (80) & Pr (64) \\
\hline Incidence of pain & $47.0 \%$ & $41.6 \%$ & $43.8 \%$ & $42.2 \%$ & $33.8 \%{ }^{*}$ & $43.8 \%$ \\
0 (No pain) & 53 & 52 & 9 & 52 & 53 & 36 \\
1 (mild pain) & 39 & 32 & 2 & 32 & 25 & 21 \\
2 (moderate pain) & 8 & 5 & 5 & 6 & 2 & 7 \\
3 (severe pain) & 0 & 0 & 0 & 0 & 0 & 0 \\
\hline
\end{tabular}

PF: Propofol \& sufentanil, PS: propofol \& sufentanil, PR: propofol \& remifentanyl, Pf: propofol \& half-sufentanil, Ps: propofol \& half-sufentanil, Pr: propofol \& half-remifentanyl. The values are shown as the number of patients (\%). ${ }^{*}, \mathrm{p}<0.05$ compared to the PF group.

characterized as analgesic agents due to their effects on decreasing perception of pain and reaction to pain as well as increasing pain tolerance. Opioids work via binding to opioid receptors, which are found principally in the central and peripheral nervous system and the gastrointestinal tract ${ }^{27}$. They are frequently used to treat acute pain and alleviate sever, chronic pain. Our study provided a reasonable anesthesia method for gastrointestinal endoscopy using propofol in combination with opioids to reduce the pain on injection of propofol and less drug dose to reduce anesthesia risk and complications such as arrhythmias and then save medical expenses, which has a certain degree of social and economic benefit.

\section{Comparison of anesthesia effect of propofol via different combinations of fentanyl, sufentanil or remifentanil}

Pretreatment with opioids has been reported to reduce the incidence and severity of pain during a propofol injection with opioids. Fentanyl, sufentanil and remifentanil appear to be a very titratable opioid providing profound intraoperative analgesia ${ }^{28-30}$. In the report by $\mathrm{Han}^{15}$, combination of a pretreatment with remifentanil and premixture of lidocaine and microemulsion propofol displayed effective function in reducing the incidence of pain on an injection of microemulsion propofol ${ }^{31}$. It was suggested that in combination with propofol $2 \mathrm{mg} / \mathrm{kg}$, an appropriate dose of remifentanil was $2 \mu \mathrm{g} / \mathrm{kg}^{32}$. This scheme achieved good anesthetic effect, but always brought some side effects, such as respiratory and HR depression and desaturation ${ }^{33}$. Similarly, in current study, the patients in the PR group appeared respiratory and HR depression, and need the respiratory support and assistance of atropine. Therefore, PR was not a desirable strategy for sedation during gastrointestinal endoscopy.

In other five groups, the side effects, such as respiratory and HR depression, were not occurred.. Recent study found that patients who received fentanyl $100 \mu \mathrm{g}$, preceded by manual venous occlusion for 1 minute, had significantly less pain on injection than 
those who received placebo, but fentanyl $50 \mu \mathrm{g}$ was ineffective for reducing such pain ${ }^{34}$. So in present study, we increased the amount of fentanyl, and the effect was acceptable. It should be noted that there was no body movement in Ps group, and times of eyelashreflex, manipulate time and revival time were lower when compared to other 4 groups, which mean that the anesthesia effect of Ps group was the best. Additionally, the incidence of pain in Ps group (34.5\%) was significantly lower than other five groups. Sufentanil is a powerful synthetic opioid analgesic drug, approximately 5 to 10 times more potent than fentanyl. The halflife $\left(\mathrm{t}_{1 / 2}\right)$ of sufentanil is $2.1 \mathrm{~min}$, and the plasma protein binding rate is $92.5 \%$, which is higher than fentanyl (44\%). Since the small volume of distribution short period of terminal elimination and thus less accumulation, sufentanil has a good controllability ${ }^{35}$. Recent study demonstrated that the patients receiving sufentanil $0.2 \mu \mathrm{g} / \mathrm{kg}$ and propofol $1-2 \mathrm{mg} / \mathrm{kg}$ for induction of anesthesia achieved good anesthetic effect, but they produced depression in systolic and diastolic blood pressures during the anaesthesia ${ }^{36}$. So the dose of sufentanil in our study was reduced to 0.1 or $0.05 \mu \mathrm{g} /$ $\mathrm{kg}$, and this strategy produced desirable efficacy, especially when using the dosage of $0.05 \mu \mathrm{g} / \mathrm{kg}$.

In conclusion, the program that $0.05 \mu \mathrm{g} / \mathrm{kg}$ sufentanil (diluted with normal saline) was administered intravenously for $30 \mathrm{~s}$ and $60 \mathrm{~s}$ later the propofol of $1-2 \mathrm{mg} / \mathrm{kg}$ were given for $60 \mathrm{~s}$ is the most suitable for gastrointestinal endoscopy.

\section{References}

1. Ellett MLC. A literature review of the safety and efficacy of using propofol for sedation in endoscopy. Gastroenterol Nurs. 2010 MarApr;33(2):111-7. doi: 10.1097/SGA.0b013e3181d601fb.

2. Haeseler G, Karst M, Foadi N, Gudehus S, Roeder A, Hecker H, Dengler R, Leuwer M. High $\square$ affinity blockade of voltage $\square$ operated skeletal muscle and neuronal sodium channels by halogenated propofol analogues. Br J Pharmacol. 2008 Sep;155(2):265-75. doi: 10.1038/bjp.2008.255.

3. Trapani G, Latrofa A, Franco M, Altomare C, Sanna E, Usala M, Biggio G, Liso G. Propofol analogues. Synthesis, relationships between structure and affinity at GABAA receptor in rat brain, and differential electrophysiological profile at recombinant human GABAA receptors. J Med Chem. 1998 May;41(11):1846-54. PMID: 9599235

4. Shafer A, Doze VA, Shafer SL, White PF. Pharmacokinetics and pharmacodynamics of propofol infusions during general anesthesia. Anesthesiology. 1988 Sep;69(3):348-56. PMID: 3261954.

5. Amornyotin S, Srikureja W, Chalayonnavin W, Kongphlay S. Dose requirement and complications of diluted and undiluted propofol for deep sedation in endoscopic retrograde cholangiopancreatography. Hepatobiliary Pancreat Dis Int. 2011 Jun;10(3):313-8. PMID: 21669577.

6. Kwak K-H, Ha J, Kim Y, Jeon Y. Efficacy of combination intravenous lidocaine and dexamethasone on propofol injection pain: a randomized, double-blind, prospective study in adult Korean surgical patients. Clin Ther. 2008 Jun;30(6):1113-9. doi: 10.1016/j. clinthera.2008.05.019.

7. Agarwal A, Ansari MF, Gupta D, Pandey R, Raza M, Singh PK, Dhiraj S, Singh U. Pretreatment with thiopental for prevention of pain associated with propofol injection. Anesth Analg. 2004 Mar;98(3):683-6. PMID: 14980919.

8. Miner JR, Burton JH. Clinical practice advisory: emergency department procedural sedation with propofol. Ann Emerg Med. 2007 Aug;50(2):182-6. PMID:17321006

9. Fujii Y, Itakura M. A comparison of pretreatment with fentanyl and lidocaine preceded by venous occlusion for reducing pain on injection of propofol: a prospective, randomized, double-blind, placebo-controlled study in adult Japanese surgical patients. Clin Ther. 2009 Oct;31(10):2107. doi: 10.1016/j.clinthera.2009.10.012.

10. Gerlach K, Uhlig T, Hüppe M, Nowak G, Schmitz A, Saager L, Grasteit A, Schmucker P. Remifentanil-propofol versus sufentanilpropofol anaesthesia for supratentorial craniotomy: a randomized trial. Eur J Anaesthesiol. 2003 Oct;20(10):813-20. PMID: 14580051.

11. Martorano P, Aloj F, Baietta S, Fiorelli A, Munari M, Paccagnella F, Rosa G, Scafuro M, Zei E, Falzetti G. Sufentanil-propofol vs remifentanil-propofol during total intravenous anesthesia for neurosurgery. A multicentre study. Minerva Anestesiol. 2008 Jun;74(6):233-43. PMID: 18414368.

12. Mayes S, Ferrone M. Fentanyl $\mathrm{HCl}$ patient-controlled iontophoretic transdermal system for the management of acute postoperative pain. Ann Pharmacother. 2006 Dec;40(12):2178-86. PMID: 17164395.

13. Savoia G, Loreto M, Gravino E. Sufentanil: an overview of its use for acute pain management. Minerva Anestesiol. 2001 Sep;67(9 Suppl 1):206. PMID:11778119.

14. Weale N, Rogers C, Cooper R, Nolan J, Wolf A. Effect of remifentanil infusion rate on stress response to the pre $\square$ bypass phase of paediatric cardiac surgery. Br J Anaesth. 2004 Feb;92(2):187-94. PMID: 14722167.

15. Mertens MJ, Olofsen E, Engbers FH, Burm AG, Bovill JG, Vuyk J. Propofol reduces perioperative remifentanil requirements in a synergistic manner: Response surface modeling of perioperative remifentanil-propofol interactions. Anesthesiology. 2003 Aug;99(2):347-59. PMID: 12883407.

16. Wehrmann T, Kokabpick S, Lembcke B, Caspary WF, Seifert H. Efficacy and safety of intravenous propofol sedation during routine ERCP: a prospective, controlled study. Gastrointest Endoscy. 1999 Jun;49(6):677-83. PMID: 10343208.

17. Jung M, Hofmann C, Kiesslich R, Brackertz A. Improved sedation in diagnostic and therapeutic ERCP: propofol is an alternative to midazolam. Endoscopy. 2000 Mar;32(03):233-8. PMID: 10718389.

18. Ahonen J, Olkkola KT, Hynynen M, Seppälä T, Ikävalko H, Remmerie B, Salmenperä M. Comparison of alfentanil, fentanyl and sufentanil for total intravenous anaesthesia with propofol in patients undergoing coronary artery bypass surgery. Br J Anaesth. 2000 Oct;85(4):533-40. PMID: 11064610.

19. Mccrirrick A, Hunter S. Pain on injection of propofol: the effect of injectate temperature. Anaesthesia. 1990 Jun;45(6):443-4. PMID: 2200300 .

20. Trihendradi C. Step by Step SPSS 18: Analisis Data Statistik. 2010.

21. Mehta CR, Patel NR. A network algorithm for performing Fisher's exact test in $\mathrm{r} \times \mathrm{c}$ contingency tables. J Am Stat Assoc. 1983 Mar;78(382):427-34. doi: 10.1080/01621459.1983.10477989.

22. Breslow N. A generalized Kruskal-Wallis test for comparing K samples subject to unequal patterns of censorship. Biometrika. 1970 Apr;57(3):579-94. doi: 10.1093/biomet/57.3.579.

23. Macario A, Weinger M, Truong P, Lee M. Which clinical anesthesia outcomes are both common and important to avoid? The perspective of a panel of expert anesthesiologists. Anesth Analg. 1999 
May;88(5):1085-91. PMID: 10320175.

24. Liljeroth E, Grauers A, keson J. Pain on injection of propofol with or without infusion of carrier fluid. Acta Anaesthesiol Scand. 2001 Aug;45(7):839-41. PMID: 11472284.

25. Stokes D, Robson N, Hutton P. Effect of diluting propofol on the incidence of pain on injection and venous sequelae. Br J Anaesth. 1989 Feb;62(2):202-3. PMID: 2784320.

26. Tan C, Onsiong M. Pain on injection of propofol. Anaesthesia. 1998 53(5):468-76. doi:

27. Rev P. Opioid Receptors. Pharmacol Rev. 1996 May;48567-92. doi: 10.1046/j.1365-2044.1998.00405.x.

28. Roehm K, Piper S, Maleck W, Boldt J. THIS ARTICLE HAS BEEN RETRACTED Prevention of propofol $\square$ induced injection pain by remifentanil: a placebo $\square$ controlled comparison with lidocaine*. Anaesthesia. 2003 Feb;58(2):165-70. PMID: 12625310.

29. Basaranoglu G, Erden V, Delatioglu H, Saitoglu L. Reduction of pain on injection of propofol using meperidine and remifentanil. Eur J Anaesthesiol. 2005 Nov;22(11):890-2. PMID: 16225729.

30. Iyilikci L, Balkan BK, Gökel E, Günerli A, Ellidokuz H. The effects of alfentanil or remifentanil pretreatment on propofol injection pain. J Clin Anesth. 2004 Nov;16(7):499-502. PMID: 15590252.

31. Han YK, Jeong CW, Lee HG. Pain reduction on injection of microemulsion propofol via combination of remifentanil and lidocaine. Korean J Anesthesiol. 2010 May;58(5):435-9. doi: 10.4097/kjae.2010.58.5.435.

32. Stevens JB, Wheatley L. Tracheal intubation in ambulatory surgery patients: using remifentanil and propofol without muscle relaxants. Anesth Analg. 1998 Jan;86(1):45-9. PMID: 9428849.

33. Lindholm EE, Aune E, Norén CB, Seljeflot I, Hayes T, Otterstad JE, Kirkeboen KA. The Anesthesia in Abdominal Aortic Surgery (ABSENT) Study: A Prospective, Randomized, Controlled Trial Comparing Troponin T Release with Fentanyl-Sevoflurane and Propofol-Remifentanil Anesthesia in Major Vascular Surgery. Anesthesiology. 2013 Oct; 119(4):802-12. doi: 10.1097/ ALN.0b013e31829bd883.

34. Fujii Y, Itakura M. RETRACTED: A comparison of pretreatment with fentanyl and lidocaine preceded by venous occlusion for reducing pain on injection of propofol: A prospective, randomized, double-blind, placebo-controlled study in adult Japanese surgical patients. Clin Ther. 2009Oct;31(10):2107-12. doi: 10.1016/j. clinthera.2009.10.012.
35. Meaudre E, Boret H, Suppini A, Sallaberry M, Benefice S, Palmier B. Sufentanil supplementation of sevoflurane during induction of anaesthesia: a randomized study. Eur J Anaesthesiol. 2004 Oct;21(10):793-6. PMID: 15678734

36. Hall RI, Murphy JT, Moffitt EA, Landymore R, Pollak PT, Poole L. A comparison of the myocardial metabolic and haemodynamic changes produced by propofol-sufentanil and enflurane-sufentanil anaesthesia for patients having coronary artery bypass graft surgery. Can J Anaesth. 1991 Nov; 8(8):996-1004. PMID: 1836422.

\section{Acknowledgement}

We are particularly grateful to Dr. Lijun Luo for his help.

\section{Correspondence:}

Dongping Shi

Department of Anesthesiology

Shanghai Jiading Central Hospital

$\mathrm{N}^{\mathrm{o}} .1$ North Road, Juyuan Street, Jiading District

Shanghai 201800, China

Phone: +86-021-67073174

Fax: +86-021-67073174

dongpingshi001@hotmail.com

Received: May 19, 2014

Review: July 18, 2014

Accepted: Aug 22, 2014

Conflict of interest: none

Financial source: Science and Technology Development Fund Project, Jiading District, Shanghai (No 201115).

${ }^{1}$ Research performed at Shanghai Jiading Central Hospital. 